\title{
Os discursos sobre qualidade de vida para os trabalhadores enquanto mecanismos disciplinares ${ }^{1}$
}

\author{
Sérgio Paes de Barros ${ }^{2}$ \\ Universidade de São Paulo (São Paulo, SP)
}

\begin{abstract}
O discurso sobre a promoção de qualidade de vida aos trabalhadores apresenta-se disseminado tanto em empresas como em artigos acadêmicos de Psicologia, Administração e Engenharia de Produção. Entretanto, é notável a divergência dos autores quanto à definição e a origem do termo qualidade de vida aos trabalhadores, o que nos motivou a perscrutar diversas obras da área buscando compreender como esse discurso veio a ter um lugar dentre os discursos autorizados (ou considerados verdadeiros). A análise das produções acadêmicas acerca da qualidade de vida no trabalho indicou a existência de três matrizes sobre o tema: Matriz Humanista, Matriz Sociotécnica e Matriz da Qualidade Total. Também analisamos autores que, se não constituem uma matriz referencial, apresentam uma visão crítica das propostas clássicas acerca do tema e as contextualizam em relação a outras áreas do conhecimento. Conclui-se que, ao deixar de abordar o Trabalho e atrelar-se à ideia de Estilo de Vida, os discursos que versam sobre a qualidade de vida aos trabalhadores acabaram por configurar mecanismos disciplinares de internalização de valores e de promoção de hábitos, comportamentos e atitudes considerados "saudáveis" pelos empregadores.
\end{abstract}

Palavras-chave: Psicologia Social, Psicologia do Trabalho, Saúde, Discurso, Disciplina.

The discourses about quality of life for workers as disciplinary mechanisms

The discourse about the promotion of quality of life for workers is disseminated both in companies and academic papers on Psychology, Management, and Production Engineering. However, there's a remarkable divergence among authors with regard to the definition and origin of the term quality of life for workers, something which motivated us to scrutinize many works on the area trying to understand how this discourse found a place among the authorized (or those regarded as veritable) discourses. The analysis of academic studies on the quality of work life indicated the existence of three matrices on the theme: Humanist Matrix, Sociotechnical Matrix, and Total Quality Matrix. We also analyzed authors who, if not constituting a reference matrix, present a critical view on the classic proposals addressing the theme and put them in context with regard to other knowledge areas. One concludes that, putting Work aside and connecting themselves to the idea of Lifestyle, the discourses on the quality of life for workers ended up becoming disciplinary mechanisms for the internalization of values and promotion of habits, behaviors, and attitudes regarded as "healthy" by employers.

Keywords: Social Psychology, Work Psychology, Health, Discourse, Discipline.

\section{Introdução}

São muitos os autores que definem e debatem o tema da qualidade de vida para os trabalhadores. Além da diversidade de noções ${ }^{3}$, a multiplicidade de situações do cotidiano organizacional onde esses discursos engendram práticas também configura característica fundamental desse campo.

A partir dessa situação, cabe perguntar: Como surgiram esses discursos para desenvolver a qualidade de vida dos trabalhadores?

1 Este artigo constitui um dos temas abordados na Dissertação de Mestrado do autor, orientada pela Profa. Dra. Leny Sato, do Departamento de Psicologia Social e do Trabalho do Instituto de Psicologia da Universidade de São Paulo, intitulada Programas de qualidade de vida para os trabalhadores: discurso, poder e disciplina e defendida em 2010 - Pesquisa realizada com apoio da Fapesp, processo $\mathrm{n}^{\mathrm{o}}$ 07/52304-2.

2 Psicólogo, mestre e doutorando em Psicologia Social e do Trabalho no Instituto de Psicologia da USP.

3 Preferimos o uso do termo noção ao invés de conceito por entendermos que o primeiro diz respeito a uma definição ampla, enquanto que conceito refere-se a uma definição precisa de algo. No caso do tema da qualidade de vida dos trabalhadores, o modo como os autores tendem a tratar do tema se dá por meio de noções e não de conceitos propriamente ditos. 
A multiplicidade de conceituações e práticas, apesar de ser muitas vezes incoerente e apresentar discursos que lutam por hegemonia entre si, possui uma história que, caso não explicitada, poderia apresentar a qualidade de vida para os trabalhadores como algo natural, tal como "uma evolução das práticas de gestão".

Partimos de uma discussão inicial acerca do levantamento das possibilidades históricodiscursivas para que a própria questão "como melhorar a qualidade de vida dos trabalhadores?" pudesse, ela mesma, ser formulada. Pode parecer óbvio que seja importante lutar pela qualidade de vida para os trabalhadores, porém, é justamente devido a essa "obviedade" que costumamos esquecer as raízes históricas e os interesses ocultos das práticas atuais.

A fim de compreender as inter-relações dos discursos acerca desse tema e, ao mesmo tempo, buscar suas origens e mutações, buscamos referências no método genealógico tal como proposto por Foucault $(1972,1979,1997)$. Esse método busca evidenciar a distinção entre "camadas de saber que formam o a priori, isto é, as condições para se possa conhecer ou se falar de algo e para que algo possa ser objeto de conhecimento" (Araújo, 2008, p. 38). Essa proposta distingue-se da concepção marxista de ideologia, pois não deseja separar "o falso do verdadeiro", ou mesmo definir se algo é científico ou não, mas tem como intuito compreender por quais meios tal objeto veio a ser objeto de conhecimento e como tais discursos acerca desse objeto vieram, com o passar do tempo, a ser tomados como verdade.

A análise das produções acadêmicas acerca da qualidade de vida no trabalho indicou a existência de três matrizes sobre o tema: Matriz Humanista, Matriz Sociotécnica e Matriz da Qualidade Total. Também analisamos autores que, se não constituem uma matriz referencial, apresentam uma visão crítica das propostas clássicas acerca do tema e as contextualizam em relação a outras áreas do conhecimento.

Trabalhar arqueologicamente sobre um conjunto de textos significa ter em mente que, ao mesmo tempo que esses discursos remetem a um objeto, criam o objeto. Para Foucault, é ingenuidade pensar que um discurso simplesmente remete a um objeto do conhecimento, pois, ao discursar, o sujeito do conhecimento se "faz sujeito" sobre esse objeto, constituindo-o. Com isso, toda prática de saber também constitui poder.

Sem procurar explicar os fatos como se estivesse pairando acima deles, a análise arquegenealógica se preocupa em compreender os jogos de verdade.

"A história que busca não é linear, diacrônica, causal. Esse tipo de historicidade pretende encontrar uma razão, um logos por meio do qual se decifraria o sentido da história" (Araújo, 2008, p. 7). Em vez de uma história contínua, global e causal, Foucault indaga como, quais arranjos na ordem do saber produziram determinados objetos que uma ciência pode descrever. Nesse sentido, procura-se compreender quais objetos são apresentados por determinados discursos. Em nosso caso, procuramos compreender a definição e origem atribuídos ao movimento de qualidade de vida para os trabalhadores.

À semelhança de Kuhn (2006), com sua noção de paradigma, Foucault propõe a noção de epistemes, que são disposições ou configurações de saber. Para Foucault, o discurso não está na dimensão da representação: o discurso não representa algo que existe, simplesmente. Essa seria uma relação dualista, na qual, para além do discurso, existe uma realidade à parte. Foucault, ao contrário, concebe que os objetos não preexistem ao saber: eles existem como acontecimentos, como aquilo que uma época pôde dizer por causa de certos arranjos entre o discurso e as condições não discursivas.

Desse modo, um objeto não existe antes das circunstâncias que venham a permitir que alguém possa falar dele com eficácia, produtividade e acerto. Agir de outra maneira pode levar o pesquisador do saber sobre a loucura, por exemplo, a considerar que este se desenvolveu com a criação dos hospitais para os loucos, deixando de questionar se antes desse conhecimento (que gerou poder para alguns) havia, por acaso, "algum louco". É nesse sentido que, muitas 
vezes, consideramos que o discurso sobre algum objeto científico apareceu "após" o objeto existir, ou seja, remetia a um objeto que preexistia ao conhecimento científico sobre ele, enquanto que para o arqueólogo o objeto do conhecimento foi criado concomitantemente à elaboração daquele discurso.

Ao pesquisarmos programas de qualidade de vida para os trabalhadores, não partimos da questão "como melhorar a qualidade de vida para os trabalhadores da melhor forma?" ou "como se desenvolveu essa área de promoção de qualidade de vida?". A questão, anterior a essas, é saber como essas perguntas se tornaram legítimas, sem, no entanto, assumir que havia uma demanda dos trabalhadores por melhor qualidade de vida que pudesse ter "evoluído naturalmente" para a elaboração dessas questões.

O enunciado engendra uma prática e um saber que constitui poder. A dificuldade, aqui, pela qual nos apoiamos em Foucault para não aceitar sem crítica a "tradição" de que é "óbvio" melhorar a qualidade de vida dos trabalhadores (QVT), é perguntar se essa preocupação surgiu em decorrência de grupos que se colocaram enquanto sujeitos desse enunciado, criando a demanda por qualidade de vida aos trabalhadores ao mesmo tempo que se "autocriavam" enquanto resposta a essa pergunta.

Para Machado (2006), o discurso não é um saber que se refere a alguma coisa externa a ele enquanto "objeto", pois este se constitui no próprio momento de sua enunciação.

\title{
Sobre o termo "qualidade de vida no trabalho"
}

A análise de artigos e livros sobre o tema da QVT indica, como, talvez, a única posição de consenso sobre o assunto, justamente a imprecisão do termo qualidade de vida no trabalho (Ayres, Silva \& Souto-Maior, 2004; Detoni, 2001; Fernandes, 1996; Fernandes \& Gutierrez, 1988; Heloani \& Capitão, 2003; Mônaco \& Guimarães, 2000; Rodrigues, 1998; Tolfo \& Piccinini, 2001).

Afirmar a imprecisão do termo indica que há diversidade de definições, porém, essa diversidade, como foi possível constatar no decorrer desta análise documental, não se dá de forma amigável entre os autores. Há, portanto, uma disputa semântica envolvida, na qual diferentes autores procuram fazer prevalecer sua definição de forma hegemônica. Porém, para além dessa disputa, ocorre simultaneamente uma disputa de poder (Foucault, 1997) que, por sua vez, interage na dinâmica do mercado de bens simbólicos (Bourdieu, 2005) ${ }^{4}$.

Segundo Foucault:

\begin{abstract}
Seria talvez preciso também renunciar a toda uma tradição que deixa imaginar que só pode haver saber onde as relações de poder estão suspensas e que o saber só pode desenvolver-se fora de suas injunções, suas exigências e seus interesses. [...] Temos antes que admitir que o poder produz saber (e não simplesmente favorecendo-o porque o serve ou aplicando-o porque é útil); que poder e saber estão diretamente implicados (1979, p. 27).
\end{abstract}

Devido à variedade de definições encontradas, optamos por apresentar alguns autores levando em consideração sua presença em artigos que remetem ao termo QVT. Dentre as publicações nacionais, os autores que buscam definir o termo qualidade de vida no trabalho remetem preferencialmente a Fernandes e Gutierrez (1988). Esse artigo, "Qualidade de vida no

4 "Todo ato de produção cultural implica na afirmação de sua pretensão à legitimidade cultural. Quando os diferentes produtores se defrontam, a competição se desenvolve em nome de sua pretensão à ortodoxia, ou então, para falar nos termos de Weber, ao monopólio da manipulação legítima de uma classe determinada de bens simbólicos" (Bourdieu, 2005, p. 108). O termo "produtores" de Bourdieu engloba escritores, artistas e eruditos. 
trabalho (QVT): uma experiência brasileira", por sua vez, cita outros doze artigos, todos de origem estrangeira ${ }^{5}$, o que indica ser um dos primeiros artigos sobre o tema escrito no Brasil e fundado na discussão que ocorria em outros países.

Foucault (1972), em seu Arqueologia do saber, articula os pressupostos da análise de discurso ao conceito de raridade, onde busca estar atento ao modo como determinados textos remetem uns aos outros, organizam-se em torno de uma mesma figura, convergem com instituições e práticas e podem se repetir em diferentes épocas, sob diferentes enunciados.

\section{Publicações pioneiras no Brasil sobre o tema QVT}

Nacionalmente, o trabalho de Fernandes e Gutierrez (1988) pode ser considerado pioneiro em relação ao tema $\mathrm{QVT}^{6}$, inclusive utilizando-se de citações estrangeiras, devido à falta de material nacional, e, principalmente, por conta da atenção recebida nos artigos e pesquisas que viriam a ser produzidos mais tarde.

Se as conceituações de QVT são diversas, diversas também são as possibilidades de análise de origem do termo, por isso, optamos por uma análise do uso desse termo nos artigos e livros mais citados na literatura nacional. Não só esse artigo é citado pelos vindouros, mas, também, ao situar Walton (1973) como um clássico, parece ter iniciado uma grande presença do método desse autor norte-americano nas pesquisas nacionais, que passam, em grande número, a adotar as categorias por ele propostas como método de investigação no cenário nacional (Detoni, 2001; Mônaco \& Guimarães, 2000; Rodrigues, 1998; Tolfo \& Piccinini, 2001; Xavier \& Quilici, 2006). Em Detoni (2001), revisão bibliográfica realizada pelo autor também indicou o modelo de Walton (1973) como intensamente presente no cenário nacional.

Segundo Fernandes e Gutierrez (1988, p. 30), em países como Canadá, EUA e, especialmente, a França e a Suécia, a preocupação com a qualidade de vida do trabalhador vinha se intensificando, principalmente pelo "amadurecimento da sociedade". Os teóricos da ciência comportamental preconizavam investimentos em:

[...] um sistema integrado de compensação, elevação da segurança e condições de trabalho, maior participação por parte do empregado, liberação do potencial criativo, poder de decisão a nível do próprio cargo, retroinformação sobre o desempenho, perspectivas de crescimento e outras tantas coisas que não geram custos adicionais, mas se refletem de maneira decisiva na qualidade de vida do trabalhador (Fernandes \& Gutierrez, 1988, p. 30).

Preocupados com uma sólida estruturação desse campo de atuação no Brasil, os autores afirmam a necessidade de se conceituar e compreender claramente em que consiste a QVT para que essa "tecnologia" não se transforme em um modismo dentre tantos outros que afligiram a literatura gerencial e que "têm certamente diminuído a credibilidade dos profissionais de RH” (Fernandes \& Gutierrez, 1988, p. 30). Apesar desse intuito, eles afirmam: "É preciso dizer, quanto à expressão 'qualidade de vida no trabalho', considerando-se exaustiva revisão bibliográfica sobre o tema, que não podemos atribuir-lhe uma definição consensual” (Fernandes \& Gutierrez, 1988, p. 30).

5 Apenas o artigo de Westley (1979) possuía versão traduzida para a língua portuguesa

6 Pioneiro quando considerado "específico" sobre o tema, visto que outros textos produzidos no Brasil, anteriores a esse, já remetiam à questão da QVT, porém, focando o sofrimento psíquico dos trabalhadores, como, por exemplo, Spink (1982a). 
Esse artigo pioneiro busca em Walton (1973), autor norte-americano, uma possível conceituação. Os autores desse texto são citados em praticamente todos os artigos relativos à QVT em território nacional.

Segundo Walton (1973, p. 31), "o conceito global [de QVT], além de atos legislativos que protegem o trabalhador, envolve o atendimento de necessidades e aspirações humanas, calcado na ideia de humanização do trabalho e responsabilidade social da empresa".

Fernandes e Gutierrez também buscam uma definição no autor canadense Bergeron (1982, citado por Fernandes \& Gutierrez, 1988, p. 31), para quem a QVT

[...] consiste na aplicação concreta de uma filosofia humanista pela introdução de métodos participativos, visando modificar um ou vários aspectos do meio ambiente de trabalho, a fim de criar uma nova situação, mais favorável à satisfação dos empregados da empresa.

Esses autores expõem, ainda, mais duas conceituações oriundas de publicações norteamericanas. Ginzberg et al. (1979, citados por Fernandes \& Gutierrez, 1988, p. 31) afirmam que a expressão "qualidade de vida no trabalho" pode ser usada para reunir todas as experiências de humanização do trabalho sob dois aspectos diferentes, cada um, por sua vez, compreendendo muitas facetas. Em primeiro lugar, a reestruturação do emprego ou a reformulação dos postos individuais de trabalho; em segundo, a estruturação de trabalho semiautogerenciados ou semiautônomos, nos quais a reformulação dos cargos do grupo de trabalho implica dar às pessoas certo grau de participação (informação, consulta, codecisão).

Nesse artigo brasileiro encontramos, também, uma citação de origem norte-americana que serve de referência para quase todos os artigos publicados posteriormente sobre o tema da QVT. Nadler e Lawer (1983, citados por Fernandes \& Gutierrez, 1988, p. 31) afirmam: "Qualidade de vida no trabalho é vista como uma maneira de pensar a respeito das pessoas, trabalho e organização".

\section{Sobre a origem do termo qualidade de vida no trabalho}

Não só foi possível encontrar diversas concepções de QVT, mas, também, divergem os autores em relação à origem do termo.

Nadler e Lawer (1983, citados por Fernandes, 1996; Rodrigues, 1999; e Vasconcelos, 2001) oferecem uma interessante e ampla abordagem do termo QVT, como apresentado no Quadro 1. 
Quadro 1: Conceito de QVT segundo Nadler e Lawer (1983)

\begin{tabular}{|l|l|}
\hline Concepçóes evolutivas da QVT & Características ou visão \\
\hline 1. QVT como uma variável (1959 a 1972) & $\begin{array}{l}\text { Reação do indivíduo ao trabalho. Investigava-se } \\
\text { como melhorar a qualidade de vida no trabalho } \\
\text { para o indivíduo. }\end{array}$ \\
\hline 2. QVT como uma abordagem (1969 a 1974) & $\begin{array}{l}\text { O foco era o indivíduo antes do resultado } \\
\text { organizacional; mas, ao mesmo tempo, buscava-se } \\
\text { trazer melhorias tanto ao empregado como à } \\
\text { direção. }\end{array}$ \\
\hline 3. QVT como um método (1972 a 1975) & $\begin{array}{l}\text { Um conjunto de abordagens, métodos ou técnicas } \\
\text { para melhorar o ambiente de trabalho e tornar o } \\
\text { trabalho mais produtivo e mais satisfatório. A QVT } \\
\text { era vista como sinônimo de grupos autônomos de } \\
\text { trabalho, enriquecimento de cargo ou desenho de } \\
\text { novas plantas com integração social e técnica. }\end{array}$ \\
\hline 4. QVT como um movimento (1975 a 1980) & $\begin{array}{l}\text { Declaração ideológica sobre a natureza do trabalho } \\
\text { e as relações dos trabalhadores com a organização. } \\
\text { Os termos “administração participativa" e } \\
\text { "democracia industrial" eram frequentemente } \\
\text { apontados como ideais do movimento de QVT. }\end{array}$ \\
\hline 6. QVT como nada (futuro) & $\begin{array}{l}\text { Como panaceia contra a competição estrangeira, } \\
\text { problemas de qualidade, baixas taxas de } \\
\text { produtividade, problemas de queixas e outros } \\
\text { problemas organizacionais. }\end{array}$ \\
\hline Fonte: Nader e Lawer (1983, citados por Fernandes, 1996, pro (1979 a 1982) & $\begin{array}{l}\text { No caso de alguns projetos de QVT fracassarem no } \\
\text { futuro, ela não passará de um "modismo" } \\
\text { passageiro. }\end{array}$ \\
\hline t2)
\end{tabular}

Fonte: Nadler e Lawer (1983, citados por Fernandes, 1996, p. 42).

Silva (2001) apresenta o quadro de Nadler e Lawer modificado no campo 6, "QVT como nada (futuro)". Segundo a autora:

Arrisca-se aqui alterar o quadro original que expõe a evolução e o conceito de Qualidade de Vida do Trabalhador, por considerar-se que o último item apresentado (o qual apontava, no futuro, "QVT como nada", sendo associado a um modismo passageiro), já não se aplica dentro do contexto existente em que se discute a responsabilidade social do estado, empresas, trabalhadores e sindicatos (Silva, 2001, p. 25).

A alteração proposta por Silva (2001, p. 24) é:

\begin{tabular}{|l|l|}
\hline $\begin{array}{l}\text { 6. QVT como responsabilidade do Estado, da Empresa, } \\
\text { do Trabalhador e do Sindicato (hoje e no futuro) }\end{array}$ & $\begin{array}{l}\text { É responsabilidade dos atores sociais - Estado, Empresa, } \\
\text { Trabalhadores e Sindicato - através da preocupação } \\
\text { conjunta e o compromisso com o ambiente e a } \\
\text { sociedade em geral, dentro de um contexto flexibilizado } \\
\text { em decorrência das constantes mudanças. }\end{array}$ \\
\hline
\end{tabular}

Para alguns autores, o tema da qualidade de vida no trabalho possui origens remotas. Para Rodrigues (1999) o estudo da qualidade de vida no trabalho sempre foi objeto de preocupação da raça humana, buscando facilitar ou trazer satisfação e bem-estar ao trabalhador na execução de suas tarefas. Comenta que os ensinamentos de Euclides (300 a.C.) de Alexandria sobre os princípios da geometria serviram de inspiração para a melhoria do método de trabalho dos agricultores às margens do Nilo, assim como a Lei das Alavancas, de Arquimedes, formulada em 287 a.C., veio a diminuir o esforço de muitos trabalhadores. 
Segundo Vasconcelos (2001) e França, Bosquetti e Veloso (2005), muitos pesquisadores contribuíram para o estudo sobre a motivação, satisfação e insatisfação do indivíduo no trabalho. Herzberg, McGregor e Maslow seriam considerados um segmento dos movimentos de qualidade de vida no trabalho, à medida que estudavam fatores organizacionais que funcionassem como incentivadores ou coibidores de motivação do funcionário.

Segundo França, Bosquetti e Veloso (2005, p. 2):

[...] determinar a origem da preocupação com a saúde no trabalho pode significar estudar a origem da transformação da natureza pelo homem. Ou seja, a partir do momento em que o ser humano se utiliza de ferramentas e cria métodos para aperfeiçoar sua forma de subsistência, procurando de alguma forma reduzir seu esforço e diminuir seu sofrimento, pode-se dizer que há embutido o conceito de saúde atrelado ao trabalho.

\section{Origem do termo QVT e a Escola Sociotécnica}

França, Bosquetti e Veloso (2005) afirmam que, ao longo da história, é possível perceber diversas referências cujo foco é entender a relação do indivíduo com seu trabalho. Destacam que, apesar de contribuírem para que o trabalho ganhe em qualidade de vida, o movimento de qualidade de vida no trabalho possui origens "formalmente delimitadas na história do pensamento administrativo". Afirmam:

O movimento conhecido como QVT tem suas origens formais vinculadas ao desenvolvimento da abordagem sócio-técnica. O movimento conhecido como Relações Humanas, desenvolvida principalmente pelos estudos de Elton Mayo na Western Electric e de Eric Trist no Tavistock Institute of Human Relations de Londres, foi um ponto de partida para os estudos de QVT (França, Bosquetti \& Veloso, 2005, p. 3).

Segundo Vieira (1996), Eric Trist, Ken Bamforth e outros, integrantes do Tavistock Institute em 1950, estudaram variáveis que futuramente serviriam para desenvolver o conceito de QVT. Citam Moraes et al. (1996) como autores que apontam o trabalho de Trist como um modelo que engloba indivíduo, trabalho e organização, visando à estruturação do trabalho, assim como à satisfação dos funcionários. Comentam que, durante as décadas de 1950 e 1960, principalmente nos Estados Unidos, o movimento de pesquisa em QVT teve uma rápida ascensão no meio acadêmico, período que coincide com o auge do fordismo e, concomitantemente, com movimentos de reivindicação coletiva, com a expansão e consolidação do movimento sindical (Heloani, 1994).

Segundo Heloani (2003), Eric Trist afirma que a origem do termo QVT concerne a uma conferência internacional sediada em Arden House, em 1972, cujo tema principal versava sobre os "sistemas sociotécnicos".

França, Bosquetti e Veloso (2005) ressaltam que o termo ${ }^{7}$ qualidade de vida no trabalho teria surgido de forma precisa em 1970, nos Estados Unidos, com Louis Davis. Algum tempo depois da definição do termo, esse pesquisador criou o Center for Quality of Working Life, na Califórnia, e mantinha contato com os pesquisadores do Tavistock Institute e teria sido influenciado pelas pesquisas realizadas nesse instituto. Durante a década de 1970, proliferam nos Estados Unidos centros de estudos sobre o tema, aliando, não ingenuamente, temas de

7 Os autores citados escrevem "conceito", porém, preferimos nos referir à mesma definição de QVT como "termo" ou "noção", visto que a amplitude de definições encontradas nos diversos autores não indica ser adequado o uso da palavra "conceito", o que poderia passar uma impressão de "unidade" entre os autores. 
QVT e produtividade. Segundo os autores citados, juntamente com centros de pesquisa em QVT é criada a National Comission on Productivity nos EUA.

A crise do petróleo, porém, fez com que os investimentos em estudos sobre QVT fossem reduzidos, tanto pelo governo como pelas empresas, que passaram a focar sua sobrevivência, deixando os interesses dos funcionários em segundo plano (Vieira, 1996). Segundo França, Bosquetti e Veloso (2005), os estudos acerca da QVT foram retomados em 1980, por pesquisadores focados no tema, chamados de "formalmente pertencentes à área de QVT", como Walton (1973) e Hackman \& Lawer (1971, citados por França, Bosquetti e Veloso, 2005).

\title{
Segundo Spink (2003):
}

\begin{abstract}
A teoria sociotécnica foi associada também com uma série de observações sobre a democracia no local de trabalho, entre elas a de que quando as pessoas têm a liberdade de se organizarem em torno das tarefas produtivas, elas tendem a criar modelos de organização flexível, nos quais as tarefas são compartilhadas e se desenvolvem habilidades múltiplas (os chamados agrupamentos semiautônomos). Esse tipo de organização tem uma capacidade adaptativa em relação às flutuações do processo produtivo e propicia melhorias na qualidade de vida dos trabalhadores. Quando, ao contrário, a parte técnica é projetada de maneira independente (obedecendo à lógica da máquina), o resultado é uma série de restrições às possibilidades de organização social (p. 117).
\end{abstract}

Dentro da abordagem Sociotécnica, podemos perceber a ligação entre a qualidade de vida dos trabalhadores e o poder destes em negociar modificações dentro dos processos de organização do trabalho. Dentre as abordagens que se debruçam sobre o tema da QVT, a Sociotécnica foi a única a ter seu nome vinculado à ideia de democracia industrial.

Biazzi Jr. (1994) afirma que um importante achado de Trist e seus colaboradores é o fato de que a elaboração de uma nova organização do trabalho caberia aos próprios trabalhadores, contrariando a administração científica. Nesse sentido, a abordagem Sociotécnica difere completamente do "Enriquecimento do trabalho" ${ }^{8}$ proposto por Herzberg (1959), no qual o trabalho é enriquecido para o operário, sem que ele participe do processo.

Essa abordagem chegou ao Brasil entre o final da década de 1970 e o início da década de 1980 (Spink, 2003), justamente quando a abertura democrática começava a tomar forma, porém, segundo esse autor, a cisão entre a realidade de dentro da fábrica e o processo democrático nacional impediu que a emancipação do trabalhador se fizesse junto à do cidadão.

As ideias referentes à "qualidade total", por sua vez, também colaboraram com o desenvolvimento de processos ligados à qualidade de vida dos trabalhadores.

\section{QVT como decorrência do modelo de qualidade total}

Vimos que o uso do termo QVT, por mais que seja impreciso, possui referências datadas antes da década de 1980. Porém, alguns autores afirmam que, na prática, a QVT aparece em decorrência do modelo de qualidade total. Segundo Barros (2003, p. 15):

O modelo de Qualidade Total, como instrumento de gerenciamento da produção, se substancia a partir da década de 80 , tendo sua origem na engenharia e visando, especialmente, a processos e controles produtivos e tecnológicos da fabricação do produto.

8 O Enriquecimento do trabalho consistiria numa constante substituição das tarefas mais simples por outras mais complexas, seguindo o crescimento individual do empregado, de forma a oferecer-lhe condições permanentes de desafio e satisfação profissional. 
Com a evolução do conceito de Qualidade Total para serviços, abriu-se nova discussão sobre a necessidade de incluir nele o conceito de Qualidade Pessoal e, consequentemente, o de Qualidade de Vida no Trabalho como parte dos Programas de Qualidade Total.

Segundo Zavattaro (1999) e Lacaz (2000), a noção de "qualidade de vida no trabalho" está fortemente sustentada nas inovações introduzidas nas empresas a partir da metade dos anos de 1980, quando os "programas de qualidade total" disseminaram técnicas visando a aprimorar a qualidade do processo e do produto/serviço por elas oferecidos.

O programa de qualidade total visa a melhorar o desempenho da empresa em três dimensões: o produto em si, da concepção à venda; o ambiente interno; a mobilização de todos os trabalhadores.

O ponto nevrálgico da QVT é justamente a mobilização de todos os trabalhadores da empresa. Planos de metas são elaborados e somente o envolvimento geral pode possibilitar seu cumprimento. É justamente nessa dimensão que aparecem como preocupação dos gestores as questões acerca da motivação dos trabalhadores e o quanto estes estão satisfeitos com a empresa.

"Os Programas de Qualidade Total exigem pessoas que saibam fazer e principalmente que queiram fazer mais e melhor, por isso precisam contar com empregados satisfeitos" (Fernandes \& Gutierrez, 1988, p. 31).

Em sua cartilha sobre a qualidade total, o Serviço Brasileiro de Apoio às Micro e Pequenas Empresas (2006) afirma:

É possível ter o máximo controle sobre os colaboradores, determinar normas rígidas, supervisionar, fiscalizar. Mas nada será tão eficaz quanto o espírito de colaboração e iniciativa daqueles que acreditam no trabalho.

Essa afirmação da Cartilha de Qualidade Total do Serviço Brasileiro de Apoio às Micro e Pequenas Empresas (Sebrae) demonstra claramente que o "espírito de colaboração e iniciativa daqueles que acreditam no trabalho" é um importante mecanismo de controle que o próprio trabalhador internaliza, sendo mais eficaz, inclusive, que imposições externas.

Objetivando o aumento da qualidade e da produtividade nas empresas, através da eliminação de desperdícios com materiais, diminuição de refugos, do custo com a mão de obra, do custo final do produto e a busca de uma maior participação dos trabalhadores nas decisões operacionais (Rechziegel \& Vanalle, 1999), a gestão da qualidade total é buscada através de práticas como a do gerenciamento do ser humano (Campos, 1992, citado por Rechziegel \& Vanalle, 1999, p. 33), definida por esse autor como "um conjunto de princípios e práticas adotadas pela organização como forma de utilizar cada vez mais a mente do indivíduo e não somente a força braçal". Além disso:

QVT é uma evolução da Qualidade Total. É o último elo da cadeia. Não dá para falar em Qualidade Total se não se abranger a qualidade de vida das pessoas no trabalho. $\mathrm{O}$ esforço que tem que se desenvolver é de conscientização e preparação para uma postura de qualidade em todos os sentidos (Albuquerque \& França, 1998, citados por Limongi-França \& Oliveira, 2005, p. 29).

Nesse sentido é que encontramos as apropriações ocidentais dos círculos de controle da qualidade (CCQ) propostos por Ishikawa (Rechziegel \& Vanalle, 1999), onde parte da responsabilidade pelo controle da qualidade foi transferida aos trabalhadores. A qualidade da mercadoria está associada a uma suposta qualidade da mão de obra, pensada também pela lógica da mercadoria. 
Se, por um lado, existem propostas para a QVT como humanização do ambiente de trabalho, com certeza é em sua interface com programas de qualidade total que a QVT aparece claramente como uma estratégia voltada para a confecção do "produto perfeito", perfeito em sua concepção e em todas as etapas de sua elaboração. A ideia de "perfeição" é tratada como um atributo que vem agregar valor ao produto, tal como uma garantia de qualidade.

Podemos compreender, portanto, o por que de se encontrar no mercado brasileiro a prática do Benchmarking ligado à área de QVT, que é a prática de se associar a marca da empresa à ideia de qualidade de vida no trabalho, onde a empresa busca tornar-se referência para outras empresas em ações com esse tema e, com isso, acaba por "agregar valor" ao nome da empresa.

Limongi-França e Oliveira (2005), ao explicitarem o modelo de QVT da Empresa Serasa, por ocasião de um estudo de caso a respeito dessa empresa, vencedora do Prêmio Nacional de Qualidade em duas oportunidades (1995 e 2000), afirmam:

No aspecto Qualidade de Vida no Trabalho, são muitas as ferramentas e metodologias que visam criar e manter um ambiente de trabalho seguro, saudável e agradável. O processo de Qualidade de Vida é alinhado com o processo da Qualidade Total, e tem o objetivo de proporcionar aos funcionários o gerenciamento de sua saúde e estilo de vida, condições de bem-estar pessoal e profissional, melhoria dos relacionamentos interpessoais, visando o equilíbrio entre mente e corpo, desenvolver de forma proativa a melhoria da satisfação com o trabalho, melhoria das práticas de saúde e redução de riscos.

\section{Autores de perspectiva crítica ao tema}

Ao situarmos alguns autores como "autores de perspectiva crítica ao tema", não estamos situando, necessariamente, os autores não citados como "acríticos", mas tão somente distinguimos, aqui, os autores de artigos que visam a refletir sobre o papel da QVT enquanto manutenção do status quo, tratando do tema sem o comprometimento de "fortalecer o movimento de QVT", como a maioria dos autores citados anteriormente.

Segundo Heloani e Capitão (2003, p. 105):

[...] o discurso manifesto encontrado nos folhetins que tratam das relações de trabalho parece demonstrar insistente preocupação com a melhoria da qualidade de vida dos que trabalham. Todavia, encontra-se uma política mundial de ajuste de custos que leva governos e empresas a minguarem as conquistas sociais alcançadas no último século pela classe trabalhadora.

Em geral, na literatura de mercado direcionada aos profissionais de Recursos Humanos e administradores, o tema da QVT raramente é tratado em diálogo com reflexões acerca do contexto histórico-político nacional. As flexibilizações das relações de trabalho, principalmente seu reflexo no surgimento de um exército de mão de obra desempregada, influem diretamente nas possibilidades de negociação dos trabalhadores por melhores condições de trabalho, e, portanto, melhor qualidade de vida enquanto trabalhadores, num contexto de precarização do trabalho.

"O que se constata é que a qualidade de vida do trabalhador, especialmente dos que vivem no terceiro mundo, vem-se degradando dia após dia" (Heloani \& Capitão, 2003, p. 105). Segundo os autores, o encolhimento do mercado de trabalho tem restringido a luta dos 
trabalhadores a preocupações cada vez mais próximas às do início do século passado, como tão somente a sobrevivência.

Para esses autores, as relações de trabalho ficam ainda mais desumanas e aéticas diante da "competitividade desenfreada e [d]os programas de qualidade total associados à produtividade e dissociados da QVT” (Heloani \& Capitão, 2003, p. 106). A qualidade de vida seria, portanto, influenciada tanto pelas condições laborais quanto pela relação direta entre os trabalhadores, sendo que esses dois fatores se deterioram rapidamente em tempos de acirramento de competitividade.

Rechziegel e Vanalle (1999) afirmam que o acirramento da competitividade e a luta por um produto de qualidade total levou à implementação das políticas de qualidade total, trazendo influências diretas sobre a qualidade de vida dos trabalhadores. Segundo esses autores:

\begin{abstract}
Algumas empresas conseguiram reduzir significativamente seus custos e aumentar sua produtividade, competitividade e lucratividade com a implantação da qualidade total, mas o mesmo não pode ser observado em relação aos funcionários, que não obtiveram aumentos reais em seus ganhos nessa mesma proporção, demonstrando que há contradições nessa "parceria" (Rechziegel \& Vanalle, 1999, p. 36).
\end{abstract}

O debate sobre a qualidade de vida no trabalho e os problemas de saúde que afetam os trabalhadores também tem sido desenvolvido em torno da questão sobre a gênese desses problemas e, por conseguinte, o locus de intervenção. Basicamente, duas têm sido as leituras: a primeira considera imprescindível estudar os contextos nos quais as pessoas trabalham e a segunda compreende a gênese desses problemas como adstritos à esfera intraindividual.

Sobre esse tema, Kompier e Kristensen (2003) elaboram revisão bibliográfica sobre as intervenções em estresse organizacional, levando em consideração as dimensões teóricas, metodológicas e práticas. Identificam que há uma preferência por intervenções no nível individual, voltadas para adaptar o trabalhador ao trabalho. Como dizem os autores, "o alvo principal é o trabalhador individual, em lugar do ambiente de trabalho ou da organização" (Kompier \& Kristensen, 2003, p. 41). Esse movimento pretere as intervenções que buscam repensar e modificar as condições e a organização do trabalho. Entretanto, como afirmara Gardell (1982), uma política voltada à melhoria da qualidade de vida e de saúde dos trabalhadores que busque adaptar o trabalhador aos esforços no trabalho transforma um problema social em problema individual. A seu ver, o caminho a ser adotado deve priorizar a leitura do contexto (condições e organização do trabalho) no qual as pessoas trabalham e estar orientado para a sua mudança. A mesma leitura é adotada por Spink (1982a, 1982b, 1991) e por Sato (1993 e 2002), que estudaram os limites e as possibilidades de replanejar o trabalho com vistas à melhoria das condições de saúde dos trabalhadores.

Porém, dividir o poder com os trabalhadores de forma a articular possibilidades concretas de replanejamento do trabalho não parece ter sido o rumo que as coisas tomaram. A participação dos trabalhadores foi transmutada na apropriação do saber do trabalhador pelo capital (Brito, 2005), o que, ao invés de dar poder ao funcionário ao possibilitar exercer seu conhecimento, configurou justamente o contrário: a empresa se apropria do conhecimento deste para se fortalecer, na mesma medida em que torna o funcionário algo descartável, desvinculado desse "capital intelectual da empresa".

A vinda da Teoria Sociotécnica ao Brasil não impediu que esta também estivesse limitada às apropriações do empresariado nacional. Segundo Spink (2003, p. 118):

A abordagem sociotécnica chegou ao Brasil entre o final da década de 1970 e o início da década de 1980; quando o processo de abertura democrática ensaiava seus primeiros passos. Entretanto, para a grande maioria das lideranças empresariais, a democracia da sociedade e o mundo dentro dos portões das fábricas eram terrenos bastante diferentes. 
Com algumas poucas exceções, as agendas empresariais e sindicais se voltaram a outras questões. Para todos os efeitos, a teoria sociotécnica virou mais um capítulo na história da administração do trabalho, arquivado junto com outros modelos e teorias do mundo préglobalizado. [...] Não ajudaram, numa época em que se valorizava cada vez mais a competência dos executivos e gerentes, as observações sobre a validade de métodos autogerenciados e sobre a capacidade dos trabalhadores de controlar processos produtivos complexos, sem supervisão.

Apesar da abundante literatura sobre o tema da QVT, percebe-se uma perspectiva com enfoque cada vez mais abstrato, com poucas referências ao cotidiano do trabalhador. Heloani e Capitão (2003) alertam para a própria precarização do trabalho dos psicólogos que atuam em departamentos de Recursos Humanos, afirmando que os processos de downsizing da atualidade vêm promovendo o esvaziamento desses departamentos e transformando os psicólogos em consultores internos, cada vez mais distantes do envolvimento direto com os trabalhadores.

Substituíram o chicote, o supervisor e os testes psicológicos pela ilusão da integração e da participação. É a tentativa da construção de uma nova subjetividade que encontra no projeto neoliberal a sementeira do individualismo e da barbárie (Heloani \& Capitão, 2003, p. 108).

É buscando a construção de uma nova subjetividade que os programas de qualidade de vida no trabalho atentam mais para o "estilo de vida" do que para as condições do trabalho propriamente ditas. Segundo Lacaz (2000, p. 153):

Ciborra e Lanzara (1985), assessores de uma central sindical italiana, criticam a noção de qualidade de vida no trabalho e propõem a terminologia qualidade do trabalho - mais adequada, na medida [em] que procura incluir todas as características de uma certa atividade humana -, apontando que ela encerra uma atividade clínica, voltada à mudança de hábitos de vida e por isso atribuindo ao próprio trabalhador a responsabilidade de adaptar-se, de modo a otimizar sua qualidade de vida e de trabalho.

Segundo esse autor, as políticas empresariais de promoção de qualidade de vida envolvem mecanismos de controle da percepção e subjetividade para "enquadrar trabalhadores mediante engrenagens que visam introjetar as normas e metas da empresa" (Lacaz, 2000, p. 153).

\section{Concluindo, o que efetivamente define e concretiza a}

[...] qualidade (de vida no) do trabalho, é o controle - que engloba a autonomia e o poder que os trabalhadores têm sobre os processos de trabalho, aí incluídas questões de saúde, segurança e suas relações com a organização do trabalho - um dos mais importantes que configuram ou determinam a qualidade de vida (no trabalho) das pessoas (Lacaz, 2000, p. 154).

\section{Considerações finais}

O tema qualidade de vida no trabalho abrange uma grande diversidade de definições, propostas práticas e mesmo tentativas de determinar a origem do termo. Se há alguma intersecção entre os autores, é justamente na comum afirmação de imprecisão do termo.

Além dessa diversidade, algo importante nos textos consultados é a preocupação, presente nos autores que buscam fortalecer o termo, de situar a "qualidade de vida no trabalho" 
como um tema nevrálgico para estudiosos em Gestão de Pessoas e de importância estratégica para departamentos de Recursos Humanos.

Segundo Fernandes e Gutierrez (1988, p. 30), “uma sólida compreensão do que consiste QVT - 'qualidade de vida no trabalho' - impedirá que tal tecnologia se transforme em mais uma entre tantas modas gerenciais que têm certamente diminuído a credibilidade dos profissionais de RH”. Outros autores confirmam tal preocupação, o que nos leva a concluir que o tema, além de uma face importante para a área de Gestão de Pessoas, constitui uma "bandeira de luta" dessa Escola da Administração que dialoga com a Psicologia Organizacional.

Os discursos vislumbrados pela análise documental indicaram a existência de algumas "matrizes". Segundo esse prisma, a QVT poderia ser compreendida mediante as matrizes Humanista, Sociotécnica e Qualidade Total.

Se, num primeiro momento, a maior parte dos livros e artigos consultados oriundos de autores ligados à Psicologia e à Administração focada em Gestão de Pessoas preconizava a promoção da qualidade de vida no trabalho como um tema ligado à Teoria Sociotécnica e condizente com uma humanização do trabalho associada a maiores possibilidades de atuação do trabalhador em planejar e interferir nos processos de trabalho, podemos perceber que, com o passar do tempo, as publicações mais atuais parecem ter cindido as partes "sócio" e "técnica", esquecendo as sugestões de interferência na técnica e detendo-se tão somente nas temáticas "sociais", a saber: a "humanização do trabalho" - ambiente agradável, estilo de vida saudável e melhoria nas relações interpessoais - sem considerar as propostas de desenvolvimento de autonomia no interior da dimensão técnica do trabalho, presentes inclusive no tão citado trabalho de Walton (1973). As análises de conjuntura sócio-política desses trabalhos costumam ater-se às caracterizações das modificações do mundo do trabalho no contexto da pósmodernidade, por vezes tratando de assuntos como flexibilização e carreiras sem fronteiras, por exemplo.

A matriz que articula a promoção em qualidade de vida do trabalhador e a filosofia da qualidade total foi encontrada quase exclusivamente em publicações oriundas das áreas de Administração Científica e Engenharia de Produção. Mais que almejar "humanização do trabalho", essas leituras tendem a buscar conciliar os altos índices de pressão por produtividade a níveis mais aceitáveis de satisfação com o trabalho. Essas publicações, ao discutir análises de contexto sócio-político, costumam falar em termos mais familiares ao trabalhador comum - em contraposição aos da matriz humanista, trazendo elementos como precarização do trabalho, trabalhos temporários e desemprego.

A matriz Sociotécnica, por sua vez, acaba sendo resgatada somente nos momentos de "fundamentação teórica" acerca das origens da QVT em trabalhos acadêmicos, não sendo devidamente aproveitada naquilo que a Teoria Sociotécnica traz de contribuição efetiva, como exposto anteriormente. Para Spink (2003, p. 118):

A abordagem sociotécnica nunca chegou a estar "na moda" em termos administrativos; mesmo que sua influência entre pessoas preocupadas com a qualidade de vida no trabalho tenha sido razoável, a ponto de ser adotada no processo de projeção de fábricas na Suécia (Volvo) e no Canadá (Shell). Em parte, sua dificuldade foi intrínseca. Não sendo uma teoria normativa, as suas respostas eram sempre abertas.

Retomar essa escola sem falar das suas principais contribuições, portanto, é tratar questões como a democracia industrial tal como discursos interditos. Nesse caso, mais que "negar" a Escola Sociotécnica, tal como exercendo o poder em sua forma repressiva, encontramos discursos que se apropriam "daquilo que este discurso pode dizer" nesta época, ou seja, daquilo que os novos sujeitos a se apoderarem dos enunciados acerca da qualidade de vida no trabalho permitem que seja dito e apresentam como sendo a totalidade do discurso dessa Escola. 
Na Arqueologia do saber (Foucault, 1972) explicita-se que há poder no próprio discurso, sendo que este suscita o desejo de sua posse, seja para servir à simbolização, seja para articular aquilo que não deve ser dito - interdito, portanto.

O discurso não é neutro, para Foucault, e a prática discursiva relaciona elementos distintos como instituições, técnicas, grupos sociais e discursos diversos. Por obedecer a uma lei da "raridade", pois nem tudo é dito por todos, torna-se alvo de disputa, de luta e não uma fonte inesgotável de interpretações, fruto da atitude exegética (Araújo, 2008, p. 67).

Segundo Foucault (1972, p. 168):

Ele aparece como um bem - finito, limitado, desejável, útil - que tem suas regras de aparição, mas também suas condições de apropriação e de realização; um bem que põe, por conseguinte, a partir de sua existência, (e não simplesmente por suas "aplicações práticas") a questão do poder; um bem que é, por natureza, objeto de uma luta, e de uma luta política.

Nossa sociedade teria inventado aparelhos para regular os corpos, mas não por meio de poderes massacrantes e de todo visíveis, mas por micropoderes. Longe de abolirem os macropoderes, os micropoderes lhes dão sustentação e multiplicam seus efeitos.

A microfísica do poder, aponta Machado (2006), remete tanto a um deslocamento do espaço de análise como do nível em que esta se efetua. O espaço de análise é alterado, pois, da anterior centralidade da figura do Estado, agora são os poderes locais os focalizados, enquanto que o nível em que essa análise se efetua passa agora a considerar a investigação dos procedimentos técnicos de poder que realizam um controle detalhado, minucioso do corpo gestos, atitudes, comportamentos, hábitos e discursos.

O poder, portanto, exerce-se mais ao dizer como agir, falar e ser, ou seja, exerce-se mais na positividade disciplinar de criação de certos sujeitos do que mediante a repressão de comportamentos e punições.

O poder possui uma eficácia produtiva, uma riqueza estratégica, uma positividade. E é justamente esse aspecto que explica o fato de que tem como alvo o corpo humano, não para supliciá-lo, mutilá-lo, mas para aprimorá-lo, adestrá-lo (Foucault, 1979, p. XVI).

A relevância dessa noção foucaultiana para o estudo de programas corporativos acerca da QVT se mostrou de forma ampla ao nos depararmos com a tendência destes em "ensinar" o trabalhador a desenvolver um estilo de vida considerado organizacionalmente saudável. Nesse sentido, percebemos que essas ações institucionais se pautavam pela positividade, ou seja, mostravam-se mais interessadas em apresentar aos trabalhadores "modos de ser" valorizados (ser criativo, atento, esbelto, calmo etc.), ao invés de reprimir comportamentos ou atitudes.

\section{Referências}

Albuquerque, L. G. \& França, A. C. L. (1998). Estratégias de recursos humanos e gestão da qualidade de vida no trabalho: o stress e a expansão do conceito de qualidade total. Revista de Administração, 33 (2).

Araújo, I. L. (2008). Foucault e a crítica do sujeito. Curitiba: UFPR.

Ayres, K. V., Silva, I. P. \& Souto-Maior, R. C. (2004). Stress e qualidade de vida no trabalho: a percepção de profissionais do setor de hotelaria. São Paulo: SEBRAE.

Barros, C. A. C. (2003) Qualidade de vida no trabalho: um ferramental para a qualidade total. Revista Cade, 6, 1518.

Biazzi Jr., F. (1994). O trabalho e as organizações na perspectiva sociotécnica. Revista de Administração de Empresas, 34 (1), 30-37. 
Bourdieu, P. (2005). Economia das trocas simbólicas (Sergio Miceli, intro., org. e sel.). São Paulo: Perspectiva.

Brito, L. M. P. (2005). Gestão de competências, gestão do conhecimento e organizações de aprendizagem: instrumentos de apropriação pelo capital do saber do trabalhador. Fortaleza: Imprensa Universitária.

Detoni, D. J. (2001). Estratégias de avaliação da qualidade de vida no trabalho: estudo de caso em agroindústria. Dissertação de Mestrado, Programa de Pós-Graduação em Engenharia de Produção, Universidade Federal de Santa Catarina, Florianópolis.

Fernandes, E. C. \& Gutierrez, L. H. (1998, outubro/dezembro). Qualidade de vida no trabalho (QVT): uma experiência brasileira. Revista de Administração da USP, 23 (4), 29-38.

Fernandes, E. C. (1996). Qualidade de vida no trabalho: como medir para melhorar. Salvador: Casa da Qualidade.

Foucault, M. (1972). A arqueologia do saber. Petrópolis, RJ: Vozes.

Foucault, M. (1979). Microfísica do poder. Rio de Janeiro: Graal.

Foucault, M. (1997). Vigiar e punir (16 ${ }^{\mathrm{a}}$ ed.). Petrópolis, RJ: Vozes.

França, A. C. L., Bosquetti, M. A. \& Veloso, H. M. (2005). A concepção gerencial dos programas de qualidade de vida no trabalho (QVT) no setor elétrico brasileiro. In Anais dos VIII Seminários em Administração (vol. 1, p. 1-15). São Paulo: Universidade de São Paulo.

Gardell, B. (1982). Scandinavian research on stress in working life. International Journal of Health Services, 12 (1), 31 41.

Heloani, R. J. (1994). Organização do trabalho e administração: uma visão multidisciplinar. São Paulo: Cortez.

Heloani, R. J. (2003). Gestão e organização no capitalismo globalizado. História da manipulação psicológica no mundo do trabalho. São Paulo: Atlas.

Heloani, R. J. \& Capitão, C. G. (2003). Saúde mental e psicologia do trabalho. São Paulo em Perspectiva, 17 (2), 102 108.

Herzberg, F. (1959). The motivation to work. New York: Wiley.

Kompier, M. A. J. \& Kristensen, T. S. (2003). As intervenções em estresse organizacional: considerações teóricas, metodológicas e práticas. Cadernos de Psicologia Social e do Trabalho, 6, 37-58.

Kuhn, T. S. (2006). A estrutura das revoluções científicas. São Paulo: Perspectiva.

Lacaz, F. A. C. (2000). Qualidade de vida no trabalho e saúde/doença. Ciência Ė Saúde Coletiva, 5 (1), 151-161.

Limongi-França, A. C. \& Oliveira, P. M. (2005, janeiro/julho). Avaliação da gestão de programas de qualidade de vida no trabalho. RAE Eletrônica, 4 (4).

Machado, R. (2006). Foucault, a ciência e o saber. Rio de Janeiro: Jorge Zahar.

Mônaco, F. F. \& Guimarães, V. N. (2000, setembro/dezembro). Gestão da qualidade total e qualidade de vida no trabalho. Revista de Administração de Empresas Contemporânea, 4 (3), 67-88.

Rechziegel, W. \& Vanalle, R. M. (1999). Qualidade de vida no trabalho e a gestão da qualidade total. Revista de Negócios, 4 (4), 31-37.

Rodrigues, C. M. C. (1998). Qualidade de vida no trabalho (QVT) e sua influência na filosofia de qualidade total: estudo realizado em nível gerencial em indústrias frigoríficas. In Anais do VIII Congresso Brasileiro de Ergonomia (pp. 863-869). Florianópolis: Associação Brasileira de Ergonomia.

Rodrigues, M. V. (1999). Qualidade de vida no trabalho: evolução e análise no nível gerencial. Petrópolis, RJ: Vozes.

Sato, L. (1993). A representação social do trabalho penoso. In M. J. P. Spink (Org.), O conhecimento no cotidiano: as representações sociais na perspectiva da Psicologia Social (pp. 188-211). São Paulo: Brasiliense.

Sato, L. (2002). Prevenção de agravos à saúde do trabalhador: replanejando o trabalho através das negociações cotidianas. Cadernos de Saúde Pública, 18 (5), 1147-1157.

SEBRAE. (2006). Principais apontamentos do Programa Negócios $\mathcal{G}$ Soluções de 26/01/2006. Tema: Qualidade Total. São Paulo: SEBRAE.

Silva, L. V. (2001). Qualidade de vida do trabalhador na Springer Carrier: uma análise dos principais programas e políticas da empresa num contexto de flexibilização do trabalho. Dissertação de Mestrado, Faculdade de Administração, Universidade Federal do Rio Grande do Sul, Porto Alegre.

Spink, P. K. (1982a, agosto). Quando trabalhar é neurotizante. Psicologia Atual, 5 (27), 16-20.

Spink, P. K. (1982b, outubro). Democracia no local de trabalho. Ou a gerência sabe o que é melhor? Psicologia Atual, 5 (28), 37-41.

Spink, P. K. (1991). Saúde mental e trabalho: o bloqueio de uma prática acessível. In F. C. B. Campos (Org.), Psicologia e saúde: repensando práticas (pp. 91-102). São Paulo: Hucitec.

Spink, P. K. (2003). A perda, redescoberta e transformação de uma tradição de trabalho: a teoria sociotécnica nos dias de hoje. Organizações e Sociedade, 10 (28), 117-130.

Tolfo, S. R. \& Piccinini, V. C. (2001). As melhores empresas para trabalhar no Brasil e a qualidade de vida no trabalho: Disjunções entre a teoria e a prática. RAC, 5 (1).

Vasconcelos, A. F. (2001, janeiro/março). Qualidade de vida no trabalho: origem, evolução e perspectivas. Caderno de Pesquisas em Administração, 8 (1), 23-35.

Vieira, A. (1996). A qualidade de vida no trabalho e o controle de qualidade total. Florianópolis: Insular.

Xavier A. A. P. \& Quilici, R. F. M. (2006). Qualidade de vida no trabalho (QVT) em uma empresa estocadora de soja na região dos Campos Gerais: um estudo comparativo sobre satisfação/motivação. In Anais do XXVI Encontro Nacional de Engenharia de Produção. Fortaleza.

Walton, R. E. (1973). Quality of working life: what is it? Sloan Management Review, 15 (1), 11-21. 
Westley, W. (1979). A qualidade de vida no trabalho: problemas e soluções. Rio de Janeiro: Incisa.

Zavattaro, H. A. (1999). A qualidade de vida no trabalho de profissionais da área de informática: um estudo exploratório. Dissertação de Mestrado, Instituto de Psicologia, Universidade de São Paulo, São Paulo.

\section{Endereço para correspondência sergiopaesdebarros@gmail.com}

Recebido em 13/10/2010

Revisado em 17/01/2012

Aprovado em 20/02/2012 